\title{
INSTRUMENTOS CULTURAIS COMO POTENCIALIZADORES DO DESENVOLVIMENTO HUMANO: UM OLHAR PARA OS ANOS INICIAIS DE ENSINO
}

\author{
CULTURAL INSTRUMENTS AS ENHANCERS OF HUMAN DEVELOPMENT: \\ A LOOK AT THE EARLY TEACHING YEARS \\ DÉBORA KÉLLI FREITAS DE MEL01 \\ JUDITE SCHERER WENZEL ${ }^{2}$
}

\section{RESUMO}

Este artigo apresenta a temática do desenvolvimento humano tendo como foco os anos iniciais e a inserção do Ensino de Ciências por Investigação. 0 objetivo consistiu em compreender como se mostram os instrumentos culturais nas falas das professoras que atuam nos anos iniciais do Ensino Fundamental ao estudarem o Ensino de Ciências por Investigação. As informações foram obtidas pelo acompanhamento da formação continuada realizada com um grupo de professoras que atua na referida etapa de ensino. A formação teve como pressuposto teórico o modelo de Investigação-Formação-Ação e da Investigação-Formação-Ação no Ensino de Ciências. 0 processo analítico foi de cunho qualitativo e teve como aporte a Análise Textual Discursiva. 0 movimento de impregnação, de unitarização e categorização nos mostrou, pela via do referencial histórico-cultural, a importância dos instrumentos culturais como modo de inserir 0 aluno na compreensão da cultura científica e, com isso, desenvolver as Funções Psicológicas Superiores.

Palavras-chave: Ensino de Ciências. Investigação. Funções Psicológicas Superiores. Prática Pedagógica.

\section{ABSTRACT}

This article presents the theme of human development focusing on the early years and the insertion of Science Teaching by Investigation. The objective was to understand how cultural instruments are shown in the speeches of teachers who work in the early years of Elementary School when studying Science Teaching by Investigation. The information was obtained by monitoring the continuing education carried out with a group of teachers who work in that stage of teaching. The training had as theoretical assumption the Investigation-Training-Action and Investigation-Training-Action model in Science Teaching. The analytical process was qualitative and had as input the Discursive Textual Analysis. The impregnation, unitarization and categorization movement showed us, through the historical-cultural referential, the importance of cultural instruments as a way of inserting the student in the understanding of scientific culture and, therefore, developing the Higher Psychological Functions.

Keywords: Science Teaching. Investigation. Superior Psychological Functions. Pedagogical Practice.

\section{RESUMEN}

Este artículo presenta la temática del desarrollo humano centrándose en los primeros años y la inserción de la Enseñanza de las Ciencias por Investigación. El objetivo fue comprender cómo se muestran los instrumentos culturales en los discursos de los docentes que trabajan en los primeros años de la Educación Primaria al estudiar la Enseñanza de las Ciencias por Investigación. La información se obtuvo mediante el seguimiento de la formación continua realizada con un grupo de docentes que laboran en esa etapa de la docencia. La formación tuvo como supuesto teórico

1 Licenciada em Física e Pedagogia. Mestranda do Programa de Programa de Pós-Graduação em Ensino de Ciências - UFFS. https://orcid.org/ 0000-0002-3625-2504. E-mail: melokelli82@gmail.com

2 Doutora em Educação nas Ciências. Professora permanente do Programa de Pós-Graduação em Ensino de Ciências - UFFS. https://orcid.org/ 0000-0002-6601-2990.E-mail: juditescherer@uffs.edu.br 
el modelo Investigación-Formación-Acción e Investigación-Formación-Acción en la Enseñanza de las Ciencias. El proceso analítico fue cualitativo y tuvo como insumo el Análisis Textual Discursivo. El movimiento de impregnación, unitarización y categorización nos mostró, a través del marco histórico-cultural, la importancia de los instrumentos culturales como una forma de insertar al estudiante en la comprensión de la cultura científica y, por tanto, desarrollar las Funciones Psicológicas Superiores.

Palabras-clave: Enseñanza de las ciencias. Investigación. Funciones Psicológicas Superiores. Práctica pedagógica.

\section{INTRODUÇÃO}

No presente artigo, procuramos compreender como se mostram os instrumentos culturais nas falas das professoras que atuam nos anos iniciais do Ensino Fundamental ao estudarem o Ensino de Ciências por Investigação (ENCI) num grupo de formação continuada. Compreendemos com a teoria histórico-cultural que o homem não nasce humano, mas se constitui humano pelas interações que ele estabelece em seu contexto cultural, social e histórico. Ao nascer, o homem é dotado de funções elementares, biológicas, as quais, de acordo com a teoria histórico-cultural, são denominadas de funções psicológicas inferiores e contemplam necessidades básicas como sentir fome, sede e frio. E, em seu desenvolvimento, o homem vai desenvolvendo funções psicológicas superiores (FPS) como: a memória, a consciência, a atenção, a fala, o pensamento, a percepção, a vontade, a formação de conceitos e a emoção (VIGOTSKI, 2009).

De acordo com Wenzel, Zanon e Maldaner (2010, p. 74), o desenvolvimento das FPS potencializa "[...] a complexificação do conhecimento e a transformação dos processos cognitivos do sujeito, ampliando a sua inteligência”. Vigotski (2009, p. 161) nos ensina que as FPS apresentam como "[...] traço comum o fato de serem processos mediatos, melhor dizendo, de incorporarem à sua estrutura, como parte central de todo o processo, o emprego de signos como meio fundamental de orientação e domínio nos processos psíquicos".

E, ao considerarmos que tais funções vão sendo desenvolvidas no decorrer da periodização do desenvolvimento humano, apontamos a escola como um espaço específico para promovê-las. Nas palavras de Rego (1995),

a escola propicia às crianças um conhecimento sistemático sobre aspectos que não estão associados ao seu campo de visão ou vivência direta (como no caso dos conceitos espontâneos). Possibilita que 0 indivíduo tenha acesso ao conhecimento científico construído e acumulado pela humanidade. Por envolver operações que exigem consciência e controle deliberado, permite ainda que as crianças se conscientizem dos seus próprios processos mentais (processo metacognitivo) (REG0, 1995, p. 79).

Nesse sentido, no entendimento de Facci (2004), a função da escola consiste em

[...] contribuir no desenvolvimento das funções psicológicas superiores, haja vista que essas se desenvolvem na coletividade, na relação com outros homens, por meio da utilização de instrumentos e signos; levar os alunos a se apropriarem do conhecimento científico atuando, por meio do ensino desses conhecimentos, na zona de desenvolvimento próximo (FACCl, 2004, p. 226). 
Ao compreendermos tal especificidade da escola, apontamos o papel central da professora ${ }^{3}$ que atua como intermediadora, aproximando o aluno do conhecimento escolar por meio do uso de diferentes instrumentos culturais, os quais se constituem elementos mediadores do conhecimento e, com a ajuda da professora, auxiliam na aprendizagem dos alunos.

Os instrumentos culturais dividem-se em dois grupos: os materiais ou ferramentas, que mediam a ação do sujeito entre os objetos, como, por exemplo, vídeos, imagens, livros, equipamentos laboratoriais, ou seja, são externos ao sujeito; e, os instrumentos psicológicos, compreendidos como signos (linguagem e símbolos), que regulam a ação sobre o psiquismo, agindo no homem de maneira análoga às ferramentas. Como segue:

Os signos não são criados ou descobertos pelo sujeito, mas o sujeito deles se apropria desde 0 nascimento, na sua relação com parceiros mais experientes que emprestam significações a suas ações em tarefas realizadas em conjunto. As interações adulto-criança em tarefas culturalmente estruturadas, com seus complexos significados, criam "sistemas partilhados de consciência" culturalmente elaborados e em contínua transformação (OLIVEIRA, 2011, p. 132).

Vigotski (1991) ressalta que os instrumentos são criados pela sociedade ao longo do curso da história humana e mudam a forma social e o nível do desenvolvimento cultural, provocando transformações comportamentais e estabelecendo uma conexão entre as formas iniciais e tardias do desenvolvimento humano. Segundo o autor,

[...] os instrumentos que o homem usa para dominar seu ambiente e seu próprio comportamento não surgiram plenamente desenvolvidos da cabeça de Deus. Foram inventados e aperfeiçoados ao longo da história social do homem. A linguagem carrega consigo os conceitos generalizados, que são a fonte do conhecimento humano. Instrumentos culturais especiais, como a escrita e a aritmética, expandem enormemente os poderes do homem, tornando a sabedoria do passado analisável no presente e passível de aperfeiçoamento no futuro (VIGOTSKI; LURIA; LEONTIEV, 2010, p. 26).

Considerando a importância do uso de instrumentos culturais como potencializadores do desenvolvimento humano, neste trabalho, procuramos identificar como se mostram, nas falas das professoras que atuam nos anos iniciais, os instrumentos culturais. As falas das professoras ocorreram num contexto de formação continuada que contemplou 0 estudo do Ensino de Ciências por Investigação (ENCI) (ANDRADE, 2011; SILVA, 2011; CARVALHO, 2019; SASSERON; DUSCHL, 2016). Ainda, importante ressaltar que o modelo de formação vivenciado esteve ancorado nos pressupostos teóricos da Investigação-Formação-Ação (IFA) (GÜLLICH, 2013) e da Investigação-Formação-Ação no Ensino de Ciências (IFAEC) (BERVIAN, 2019).

Utilizamos os aspectos do ENCl em razão de que essa abordagem propõe que a sala de aula se torne um espaço investigativo, pois com a indicação de um problema se instiga 0 aluno a participar da aula, apontar hipóteses, realizar observações para a construção dos conceitos científicos na sistematização dos resultados. Todo esse processo é conduzido com a ajuda da professora que vai auxiliando 0 aluno a estabelecer as relações necessárias para compreender a Ciência.

3 Usaremos o termo "professora" no texto, por conta de que na Educação Infantil e nos anos iniciais do Ensino Fundamental, a presença de mulheres no exercício do magistério tem sido eminente (FONTANA, 2005). 
No processo formativo recomendamos às professoras fazer 0 uso de um diário de formação, pois a escrita reflexiva ajuda-as a perceber ações que passam despercebidas em sala de aula. Pela escrita, a profissional passa a refletir sobre determinada atitude que 0 aluno ou que ela teve mediante alguma situação e, com isso, passa a ter instrumentos que a auxiliam no processo de análise, ou seja, a escrita formativa possibilita uma reflexão sobre a dinâmica da sala de aula por meio do relato sistemático e menorizado dos diferentes acontecimentos descritos pela professora. Assim, destacamos que, ao sugerir o uso do diário de formação, partimos do pressuposto de que, ao escrever sobre sua prática, a professora reflete sobre os acontecimentos, proporcionando uma tomada de consciência sobre suas ações e seus modelos de referência. Nesse movimento de escrita reflexiva, instaura-se as conexões entre os saberes práticos e os saberes disciplinares (PORLÁN; MARTíN, 1997).

A referida formação foi realizada em cinco encontros e se caracterizou como um movimento cíclico de observação, planejamento, ação, problematização, espelhamento de práticas, discussões e questionamentos, o que possibilitou às professoras participantes a reflexão na, para e sobre a prática. Esse modo de realizar a formação visa auxiliar as professoras para melhor observar, analisar e compreender as questões da sua prática e, para assim, sobre ela agir em relação a sua profissão e à função da escola na sociedade em que vivemos (CARR; KEMMIS, 1988; ALARCÃO, 2011; GÜLLICH, 2013; BERVIAN, 2019). Para o presente artigo, atentamos para os resultados que se mostraram mais significativos em uma das categorias emergentes no processo de Análise Textual Discursiva (ATD) durante 0 qual foi desenvolvido. Segue uma explicitação mais detalhada da metodologia de pesquisa e do contexto de formação que foi acompanhado.

\section{METODOLOGIA}

0 grupo, anteriormente referido, foi acompanhado e organizado por uma das pesquisadoras deste artigo e foi constituído por mais três professoras convidadas que ministram aulas para os anos iniciais do Ensino Fundamental em uma escola municipal, localizada no interior do Município de Rolador/RS.

A pesquisa é de cunho qualitativo (LÜDKE; ANDRÉ, 1986) e os dados foram analisados por meio da Análise Textual Discursiva (ATD) (MORAES; GALIAZZI, 2016), a qual foi desenvolvida seguindo os preceitos éticos, sendo que as professoras assinaram o Termo de Consentimento Livre e Esclarecido aprovado pelo Comitê de Ética em Pesquisa (CEP), autorizando o uso de suas falas para a pesquisa. No decorrer do diálogo dos resultados, as professoras serão indicadas por nomes fictícios, como Jasmim, Hortência e Íris. Por conta da pandemia da Covid-194, os encontros foram realizados mensalmente e gravados por meio da Plataforma Google Meet e tiveram duração máxima de duas horas.

0 que apresentamos, nesta análise, faz parte de uma pesquisa que busca compreender como as falas e/ou as escritas das professoras mostram a sua apropriação na compreensão sobre 0 ensinar Ciências nos anos iniciais ao serem instigadas a estudar aspectos do ENCI num movimento de IFA. As informações que constituíram o corpus de análise foram obtidas mediante as transcrições das narrativas dos cinco encontros realizados entre agosto e dezembro de 2020, das escritas no diário de formação e das respostas dadas a um questionário inicial que foi aplicado junto às professoras.

No processo analítico escolhido, "[...] os pesquisadores são convidados a desconstruírem e reconstruírem conceitos, com unitarização, categorização e produções escritas derivadas de suas análises e sínteses" (MORAES; GALIAZZI, 2016, p. 245), assim, o movimento intenso de impregnação e

4 https://www.gov. br/saude/pt-br/coronavirus/0-que-e-o-coronavirus 
leitura de todas as informações obtidas pelo corpus se mostraram muito importantes. Ressaltamos que na ATD o corpus da pesquisa

[...] é constituído essencialmente de produções textuais. Os textos são entendidos como produções linguísticas, referentes a determinado fenômeno e originadas em um determinado tempo e contexto. São vistos como produções que expressam discursos sobre diferentes fenômenos e que podem ser lidos, descritos e interpretados, correspondendo a uma multiplicidade de sentidos possíveis (MORAES; GALIAZZI, 2016, p. 38).

De posse das informações trazidas pelo corpus, iniciamos o movimento cíclico proposto pela ATD. Num primeiro momento, realizamos a unitarização, ou seja, desestruturamos as ideias apresentadas no texto inicial, transformando-as em Unidades de Significado (US). Esse movimento consiste na desfragmentação do texto e desafia o pesquisador a dar mais atenção para detalhes, para aspectos presentes no texto. Em seguida, ao reinterpretarmos as US, começa 0 outro ciclo da ATD, que se caracteriza como a categorização, que implica em aproximar o que se mostra semelhante. Desse movimento, emergiram as categorias iniciais, as quais contemplam o primeiro título dado a cada US, e, num processo mais intenso de impregnação, chegamos às categorias intermediárias. Dessas, novas aproximações se mostraram possíveis e indicamos uma categoria final, a qual contempla uma maior atribuição de significados. Em seguida, realizamos a escrita do metatexto. Nele, mencionamos a interpretação dos fenômenos e achados da pesquisa (MARTINS; LIMA, 2019).

Escolhemos duas figuras (1) e (2) que foram adaptadas de Pessano (2016) para representar um esquema mais detalhado do processo analítico desenvolvido. Ressaltamos que tal metodologia nos desafiou e nos conduziu do caos para ordem.

Figura 1 - Esquema da ATD: Unitarização.

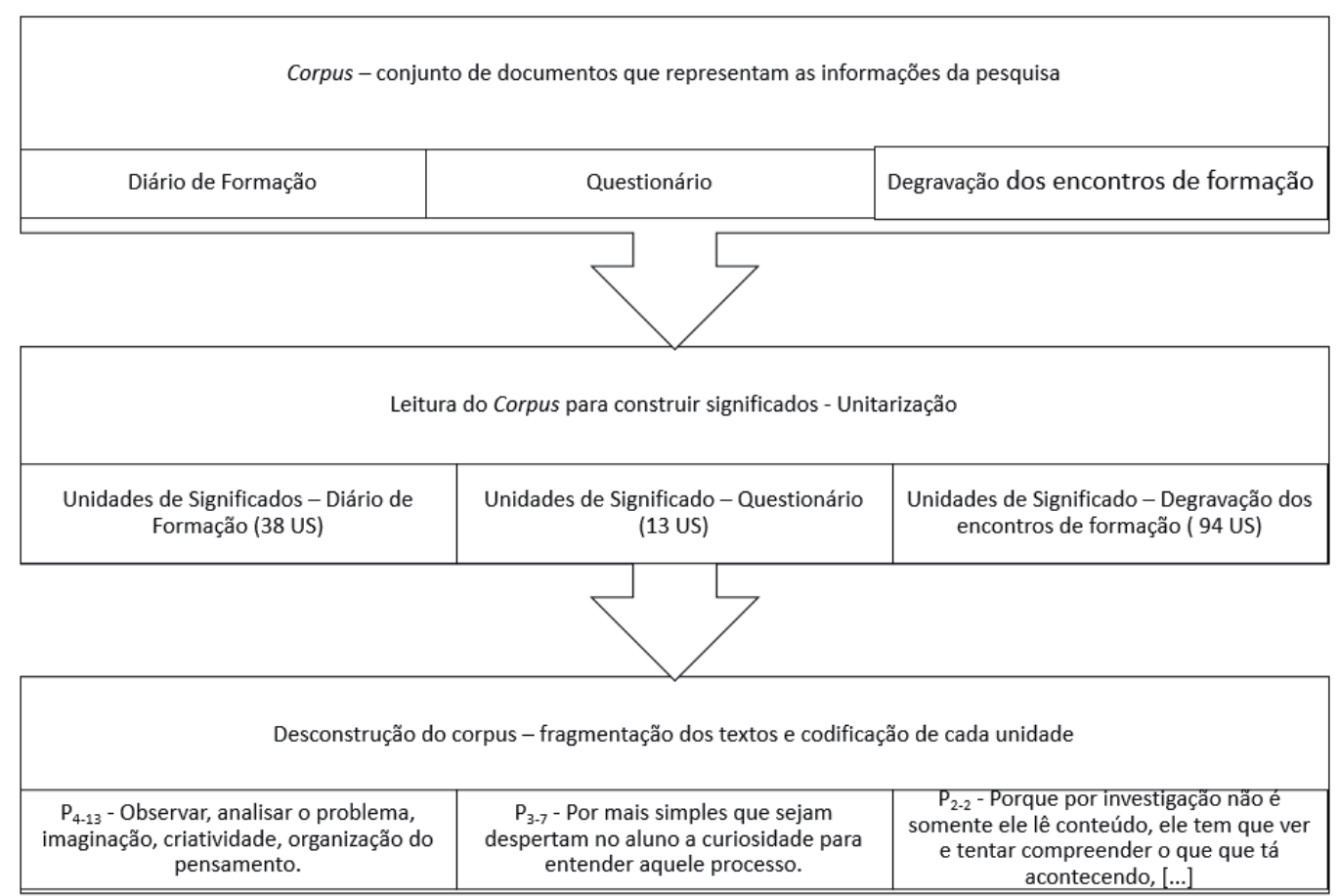

Fonte: Com base em Pessano (2016). 
Figura 2 - Esquema da ATD: Categorização e Metatexto.

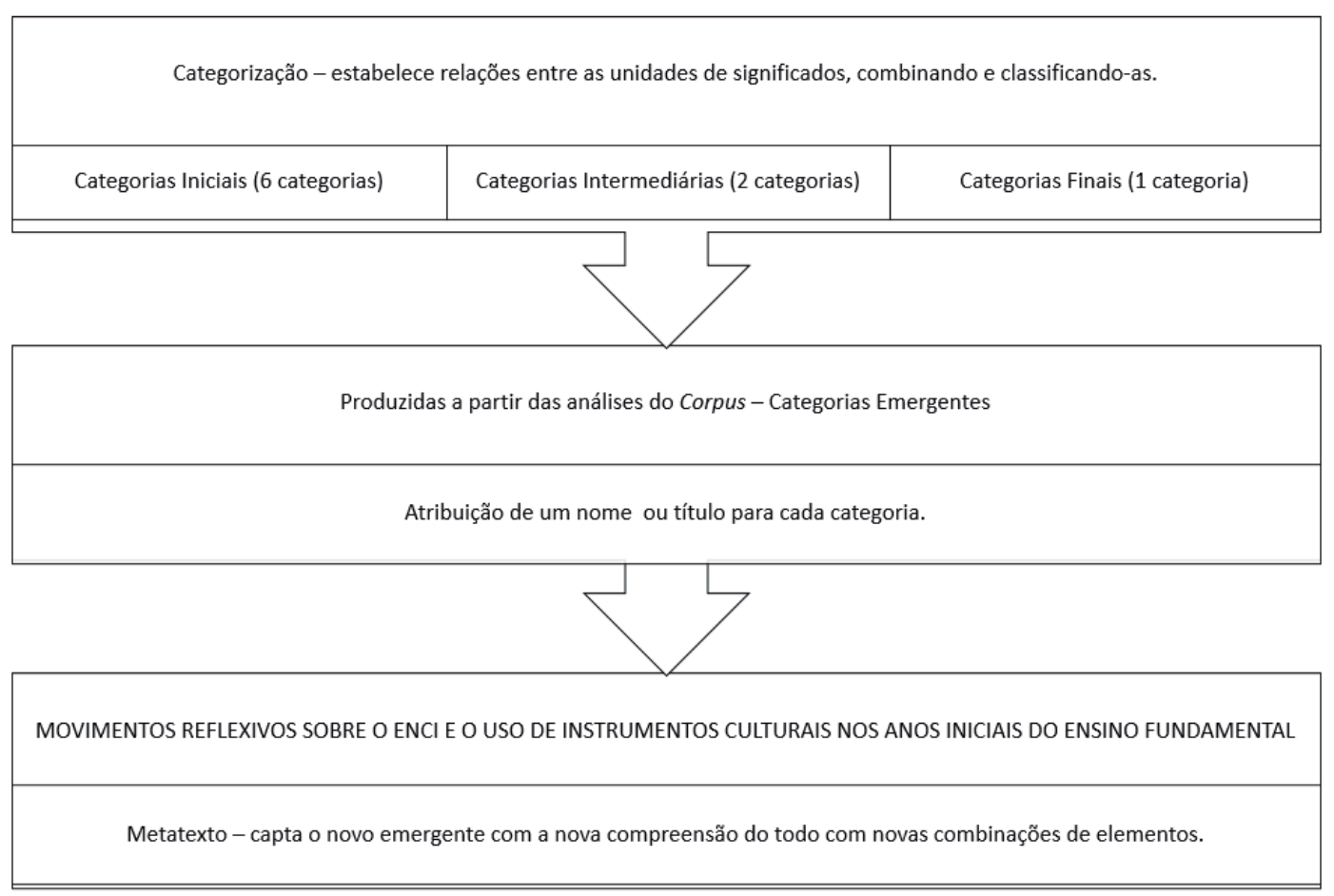

Fonte: Com base em Pessano (2016).

Para o presente trabalho, realizamos um olhar mais direcionado para a categoria inicial: movimentos reflexivos sobre o $\mathrm{ENCl}$ e 0 uso de instrumentos culturais nos anos iniciais do Ensino Fundamental. Essa categoria emergiu do agrupamento de 27 US e, após as leituras realizadas tendo como aporte 0 referencial histórico-cultural, compreendemos ser importante a atenção para como se mostram os instrumentos culturais, devido às compreensões das professoras ao indicarem o seu uso. Assim, desafiamo-nos na escrita de parágrafos sínteses que vão constituindo um metatexto para essa categoria inicial. No texto que apresentamos, tendo em vista a ATD, fizemos uso de um diálogo com as US, com o referencial teórico da pesquisa e com as nossas compreensões, e esse diálogo possibilitou novas compreensões acerca do fenômeno em estudo. As US estão apontadas em forma de citações, em itálico, com o nome da professora autora do texto e o código do processo analítico $\left(\mathrm{P}_{\mathrm{x}-\mathrm{z}}\right)^{5}$ que remete para a fonte do corpus: Diário de Formação (DF), Questionário (Q) ou Encontro de Formação (EF).

\section{MOVIMENTOS REFLEXIVOS SOBRE 0 ENCI E 0 USO DE INSTRUMENTOS CULTURAIS NOS ANOS INICIAIS DO ENSINO FUNDAMENTAL}

Nesta categoria, apontamos para as possíveis aproximações do $\mathrm{ENCl}$, para 0 uso de instrumentos culturais e para a necessidade de qualificar o uso deles, tendo em vista o desenvolvimento humano em contexto escolar. Compreendemos com Maldaner (2014, p. 27) que "os primeiros anos

$5 \mathrm{P}_{\mathrm{x}}$ - código de identificação do instrumento; $\mathrm{z}$ - número de identificação da US. 
escolares são de significação do que se poderia chamar de códigos de acesso aos bens culturais, como a linguagem escrita, os signos matemáticos, os conceitos básicos das Ciências" que possibilitam "novas funções mentais" e consolidam as anteriores, as quais o autor (2014, p. 27) exemplifica como "a concentração, a memória voluntárias, raciocínio lógico e matemático [mas isso somente é possível se] houver bons níveis de aprendizagem", ou seja, o conteúdo tem que ser significativo para 0 aluno.

Para que os alunos compreendam melhor o mundo, eles necessitam se apropriar e desenvolver as FPS, pois "não nascemos humanos, nos constituímos a partir das interações" (Íris, $\mathrm{P}_{4-32}$ DF). Essa interação entre o sujeito e o instrumento "por mais simples que sejam despertam no aluno a curiosidade para entender aquele processo" (Hortênsia, $P_{3-7,} Q$ ). No processo pedagógico, pelo acompanhamento dos alunos, é no movimento mediado que as professoras vão melhor compreender os modos de ajudar, de conduzir o ensino. Segundo Vigotski (2009),

a essa colaboração original entre a criança e 0 adulto - momento central do processo educativo paralelamente ao fato de que os conhecimentos são transmitidos à criança em um sistema deve-se 0 amadurecimento precoce dos conceitos científicos e 0 fato de que o nível de desenvolvimento desses conceitos entra na zona das possibilidades imediatas em relação aos conceitos espontâneos, abrindo-Ihes caminho e sendo uma espécie de propedêutica do seu desenvolvimento (VIGOTSKI, 2009, p. 244).

0 uso dos instrumentos culturais de forma investigativa para promover a aprendizagem do Ensino de Ciências nos anos iniciais do Ensino Fundamental tem um papel importante, pois possibilita ao aluno que se aproprie dos conceitos científicos. Essa inserção dos alunos na linguagem das Ciências depende muito da intervenção da professora, que pode apresentar ao aluno "desde problemas experimentais, com ações diretas dos estudantes sobre materiais ou na forma de demonstrações investigativas, até problemas envolvendo outros recursos, como o trabalho com figuras ou textos" (CAPECCHI, 2019, p. 26).

Assim, o desenvolvimento do aluno ocorre quando ele internaliza os instrumentos psicológicos ou signos, ou seja, quando ele consegue utilizar os conteúdos apresentados pela professora para representar os acontecimentos do seu cotidiano. Para Vigotski (2009),

a luz dessa importância central do sistema, introduzido no pensamento da criança pelo desenvolvimento dos conceitos cientíícos, fica clara também a questão teórica geral sobre as relações entre 0 desenvolvimento do pensamento e a aquisição de conhecimentos, entre a aprendizagem e o desenvolvimento (VIGOTSKI, 2009, p. 384).

As FPS são desenvolvidas a partir da apropriação cultural do aluno que é possível por meio das interações estabelecidas e mediadas pelas professoras com uso dos instrumentos culturais, como a linguagem que foi muito bem destacada pela professora Íris ao indicar que o "[...] desenvolvimento ocorre pelo uso da linguagem" (Íris, $\mathrm{P}_{4-33}$, DF). Ao considerar o Ensino de Ciências, Hortênsia aponta que é fundamental o uso de "[...] uma linguagem clara sobre os fenômenos e de acordo com o nível de aprendizado do aluno" (Hortênsia, $\mathrm{P}_{4-9}$ DF). Ela ainda destaca sobre a necessidade de "[...] adequar essa linguagem sempre que possível à faixa etária do aluno de seu desenvolvimento buscando uma melhor compreensão do fato observado" (Hortênsia, $\mathrm{P}_{4-10}$, DF). Ressaltamos que esse cuidado e atenção para com a linguagem não pode ser compreendido como um modo de simplificar, mas sim de fazer uso dos termos corretos da Ciência com a atenção para os sentidos que vão sendo 
atribuídos pelos alunos.

Com base nos pressupostos vigotskianos, a linguagem é um instrumento de comunicação e de constituição do sujeito, sendo a principal mediadora entre este e 0 objeto do conhecimento. A linguagem nos ajuda a expressar nossos pensamentos (significado da palavra) e nos permite realizar a comunicação com o outro (fala). Nesse processo de pensamento para a fala ocorrem modificações nos significados das palavras por conta das relações históricas, sociais e culturais do sujeito. Então, temos o significado propriamente dito, que é a união do pensamento e da fala, e o sentido que é a soma de todos os eventos psicológicos que a palavra desperta em nossa consciência (VIGOTSKI, 1991).

Com base nisso, a linguagem é considerada como constitutiva do sujeito e é impossível o desenvolvimento de pensamento sem palavras, pois é ela que

[...] habilita as crianças a providenciarem instrumentos auxiliares na solução de tarefas difíceis, a superar a ação impulsiva, a planejar uma solução para um problema antes de sua execução e a controlar seu próprio comportamento. Signos e palavras constituem para as crianças, primeiro e acima de tudo, um meio de contato social com outras pessoas. As funções cognitivas e comunicativas da linguagem tornam-se, então, a base de uma forma nova e superior de atividade nas crianças, distinguindo-as dos animais (VIGOTSKI, 1991, p. 23).

É nos anos iniciais do Ensino Fundamental que 0 aluno mais sente necessidade de aprender os códigos da linguagem que o leva ao estudo, porque é fortemente estimulado pelo meio sociocultural, por conta de que os membros familiares, as pessoas com quem convive, disponibilizam a ele os instrumentos culturais. Como exemplo, pode-se citar o acesso aos sites de seu interesse ou aos livros de histórias e revistas em quadrinhos, que indicam a necessidade de leitura (MALDANER, 2014).

De uma maneira mais ampla, a linguagem pode ser expressa de forma verbal, por sinais, símbolos, pela arte, pelo corpo e, de acordo com Pieper e Sangiogo (2020), pode ser associada às seguintes funções ou características: a) comunicação entre os sujeitos (relação entre o signo e 0 significado); b) existência de diferentes multimodalidades (fala, escrita, gestos, símbolo, imagens, expressão, fisionomias/sentimentos); c) mediadora nos processos de ensino e aprendizagem, construída historicamente, socialmente, pluricultural (diferente e específica) e pertencente a determinados grupos culturais; d) constituidora, reguladora e mediadora da articulação do pensamento com a realidade, presente na memória, em processos de generalização e abstração, de reflexão, de transformação e ação na realidade, com a compreensão da linguagem como constitutiva do ser humano; e e) possui assimetrias, relações de poder, não neutralidade, a exemplo da regulação de sentidos por parte do professor, que dá acesso a palavras que tem sentidos próprios. Segundo Oliveira (2011),

a linguagem permite que o mundo seja refratado na consciência humana por meio dos significados culturais selecionados pelo sujeito e por ele apropriados com um sentido próprio, embora impregnado de valores e motivos sociais historicamente determinados. A emergência da linguagem verbal, de um agir comunicacional, vai regular a atividade da criança pelo estabelecimento, por parte dos parceiros, de um acordo sobre os objetivos e as formas de ação, que podem ser então planejados e avaliados, tornando-se mais complexos. A aquisição de um sistema linguístico dá forma ao pensamento e reorganiza as funções psicológicas da criança, sua atenção, memória e imaginação (OLIVEIRA, 2011, p. 133). 
Vigotski (2009) nos apresenta estudos sobre a importância da atuação da professora como mediadora do conhecimento para a definição e o funcionamento psíquico do aluno, por conta de que ele está em um processo ininterrupto de construção e é nesse processo que ocorre 0 amadurecimento e 0 desenvolvimento das FPS. Para Oliveira (2011),

os discursos dos professores, dos pais e da mídia interagem com as condições psicológicas das crianças em cada idade, produzindo importante combinação de processos pelos quais signos culturais são pessoalmente interpretados e apropriados por elas. Assim, no processo educativo, as iniciativas das crianças de atribuir sentido são confrontadas não apenas com aspectos perceptivos dos objetos e com relações que elas podem cognitivamente estabelecer com base neles, mas também com associações e explicações de senso comum, mitos ou representações sociais, discursos científicos, religiosos, políticos ou sanitários, e com as definições dos professores (OLIVEIRA, 2011, p. 159).

Considerando o ENCl, a linguagem, em seus diferentes modos de uso, mostra-se importante, pois para que o problema proposto pela professora seja respondido é preciso percorrer um processo desde a apresentação do problema, levantamento e teste de hipóteses, construção de uma explicação para, em seguida, realizar a socialização dos resultados obtidos. Segundo Solino e Sasseron (2018),

[..] a atividade investigativa não se restringe apenas aos processos cognoscitivos de pensar, analisar, teorizar, memorizar, ou resolver o problema, mas estende-se à esfera das necessidades cognitivas dos sujeitos envolvidos. De acordo com a perspectiva histórico-cultural, são as necessidades que dirigem e regulam a atividade concreta do indivíduo, quando a mesma se encontra no objeto, isto é, quando ela se objetiva no problema a ser enfrentado e solucionado. É nesse encontro entre necessidade e problema (objeto), que este último se torna o motivo da atividade, 0 que estimula o sujeito a agir (SOLINO; SASSERON, 2018, p. 119).

Em todo esse movimento da inserção do ENCl em sala de aula, destacamos o importante papel da professora para inserir o aluno na cultura científica e na vivência da investigação e, com isso, oportunizar algumas práticas utilizadas pela cultura científica, como "pensar logicamente, observar, coletar e analisar dados, refletir e argumentar, comunicar ideias e avaliá-las, entre outras" (SOLINO; SASSERON, 2018, p. 105).

Ao promover esse movimento, em sala de aula, a professora oportuniza de forma significativa as experiências vivenciadas pelo aluno, permitindo assim, a construção de novos conhecimentos acerca do que está sendo investigado.

Porque por investigação não é somente ele lê conteúdo, ele tem que ver e tentar compreender o que que tá acontecendo nessa situação e em cima disso, ele vai questionar, ele vai criar hipóteses, ele vai botar o que o conhecimento pessoal dele, o que ele entendeu, que ele sabe e junto com o professor então eles vão criar 0 conhecimento mais concreto digamos assim, científico na verdade, mais ou menos acho isso (Hortênsia, $\mathrm{P}_{2-2,} \mathrm{EF}$ ). 
Ainda, destacamos a importância da professora explicitar ao aluno o motivo de investigar determinado fenômeno, para assim, instigar a sua participação, engajá-lo na elaboração dos meios para resolver os problemas propostos, auxiliá-lo e instigá-lo na elaboração de outras questões, na elaboração de hipóteses, ajudar a analisar os fenômenos, para assim, elaborar argumentos, socializar com os colegas os resultados obtidos. E é nesse movimento cíclico de investigação que 0 aluno vai atingir níveis mais elevados de compreensão (SOLINO; SASSERON, 2018).

É fundamental que essa atividade penetre a escola e se estenda para o meio social dos alunos, que liga motivo com ação, e que seja um caminho a ser explorado pela professora. Essa atividade precisa ser vislumbrada pela sociedade e pela escola, indicando que 0 conhecimento é verdadeiramente produzido para si, não apenas repetido sem fazer sentido. As palavras que representam os conceitos científicos devem circular em sua plenitude no ambiente escolar, durante os processos interativos professora-aluno, mesmo que 0 aluno ainda não tenha 0 significado plenamente desenvolvido, ele vai utilizá-la com naturalidade, tornando-a, posteriormente, um signo (MALDANER, 2014).

Ainda, destacamos que 0 diálogo e as escritas das professoras mostraram que $0 \mathrm{ENCl}$ requer 0 uso de instrumentos mais externos que seriam as ferramentas, tendo em vista "[...] fazer 0 aluno visualizar e tentar compreender o que está acontecendo" (Hortência, $\mathrm{P}_{2-1} \mathrm{EF}$ ) e, ao mesmo tempo, apontam o uso de instrumentos psicológicos, pois é preciso, conforme já apontamos com a professora Hortênsia, "[...] uma linguagem clara sobre os fenômenos e de acordo com o nível de aprendizado do aluno" (Hortênsia, $P_{4-9}$, DF). Segundo Scarpa e Silva (2019),

nesse contexto 0 ensino de Ciências por investigação é aquele que possibilita ao aluno, no que diz respeito ao processo de produção do conhecimento, identificar padrões a partir de dados, propor explicações com base em evidências, construir modelos, realizar previsões e rever explicações com base em evidências; em relação ao processo de validação do conhecimento, selecionar evidências para justificar uma explicação, construir argumento para relacionar dados e conclusões e empregar dados para tomar decisões; e, no que se refere ao processo de comunicação, discutir, escrever e comunicar aos colegas o conhecimento cientifico (SCARPA; SILVA, 2019, p. 132).

Nessa direção, apontamos com Íris acerca da importância da mediação da professora, a fim de que os alunos "[...] sejam desafiados pelo professor a pensar, experimentar, e chegar a conclusões aliando teoria e prática" (Íris, $\mathrm{P}_{3-3} \mathrm{Q}$ ). Vigotski (2009) ensina-nos de que, desde o primeiro momento em que 0 aluno é apresentado a úma palavra até o momento em que ele se apropria do significado e do conceito dela, ocorre o desenvolvimento de um complexo processo psicológico interior, como já apontamos com Maldaner (2014). Segundo Vigotski (2009),

o curso do desenvolvimento do conceito científico nas ciências sociais transcorre sob as condições do processo educacional, que constitui uma forma original de colaboração sistemática entre o pedagogo e a criança, colaboração essa em cujo processo ocorre 0 amadurecimento das funções psicológicas superiores da criança com 0 auxílio e a participação do adulto. No campo do nosso interesse, isto se manifesta na sempre crescente relatividade do pensamento causal e no amadurecimento de um determinado nível de arbitrariedade do pensamento científico, nível esse criado pelas condições do ensino (VIGOTSKI, 2009, p. 244). 
Ao considerar o diálogo sobre o uso do ENCl em contexto escolar, a professora Íris descreve que, por meio "da leitura de um livro, de um desenho infantil, de alguma observação" (Íris, $\mathrm{P}_{4-16}$. DF) é possível propor uma problematização para a construção do conhecimento, permitindo que 0 aluno teste as suas hipóteses, que busque informações e que, ao observar os fenômenos, com a ajuda da professora, seja capaz de fazer uso das explicações da Ciência e, assim, desenvolver as FPS, pois

a relação entre 0 uso de instrumentos e a fala afeta várias funções psicológicas, em particular a percepção, as operações sensório-motoras e a atenção, cada uma das quais é parte de um sistema dinâmico de comportamento. Pesquisas experimentais do desenvolvimento indicam que as conexões e relações entre funções constituem sistemas que se modificam, ao longo do desenvolvimento da criança, tão radicalmente quanto as próprias funções individuais (VIGOTSKI, 1991, p. 24).

0 uso dos instrumentos culturais aliados ao ENCl nos anos iniciais pode qualificar as condições de ensino para que ocorram diferentes interações entre os alunos e a professora, qualificando a construção do saber, a cooperação, a negociação, a argumentação em sala de aula e o domínio das linguagens específicas das Ciências. Todos esses processos promovem o desenvolvimento das FPS e, assim, oportuniza de fato condições de aprendizagem que contribuem na transformação cognitiva dos alunos, aprimorando o seu intelecto.

A professora, ao fazer uso da perspectiva do ENCI por meio do uso de instrumentos, auxilia 0 aluno no desenvolvimento das FPS, pois colocam em movimento vários processos de desenvolvimento que, de outra forma, não aconteceriam. Destacamos que a qualidade do desenvolvimento psicológico não é inerente a qualquer ensino, porém depende de como ele é organizado, ou seja, a atividade de ensino escolar necessita visar uma ampliação dos horizontes culturais do aluno, por intermédio da apropriação dos conhecimentos científicos, produzindo novas necessidades e tendo como meta o desenvolvimento da personalidade do aluno como um todo (EIDT; DUARTE, 2007).

Com base nisso, destacamos que as informações pinceladas do corpus de análise evidenciaram que os a) instrumentos materiais ou ferramentas: vídeos, imagens, livros, equipamentos laboratoriais; e b) os instrumentos psicológicos (signos): linguagem e escrita; são utilizados como auxiliares no desenvolvimento humano, e mostraram-se presentes no desenvolvimento do ENCI em contexto escolar.

\section{CONCLUSÃO}

No contexto do grupo de formação, as professoras foram desafiadas a repensar a sua prática pedagógica a partir do ENCl. Nesse movimento, foram dialogando sobre alternativas para tal ensino e, com isso, mostrou-se com força o uso dos instrumentos culturais. Nessa direção, buscamos compreender mais sobre a relação do uso de instrumentos culturais, sobre 0 ENCl e sobre 0 desenvolvimento humano. Com isso, aproximamo-nos do referencial histórico-cultural, com o qual compreendemos mais sobre as FPS.

De um modo geral, destacamos que a análise da categoria inicial, objeto do metatexto que apresentamos, possibilita-nos afirmar que os instrumentos culturais se mostram constituintes do $\mathrm{ENCl}$, pois potencializam a interação com 0 aluno, estimulando a curiosidade e a imaginação, equilibrando o nível de dificuldade do problema e o nível de curiosidade, para que ele não perca o interesse e, as- 
sim, possa ir se inserindo na cultura científica de modo a identificar a aprendizagem sobre o olhar da Ciência e adquira o domínio da linguagem científica.

0 processo de ensino realizado pela mediação da professora com 0 uso dos instrumentos culturais, juntamente com a abordagem do ENCI, implica positivamente na aprendizagem do aluno, propiciando que ele desenvolva as FPS por meio da busca de informação, da elaboração de argumentos, da autonomia, do trabalhar em grupo, da capacidade de concentração, de organização, da manipulação de equipamentos, aprende a importância da observação de fenômenos, de realizar 0 registro sistematizado dos dados, da formulação e do teste de hipóteses.

Nesse sentido, afirmamos a necessidade de os conceitos científicos serem ensinados desde os anos iniciais do Ensino Fundamental para o desenvolvimento psicológico dos alunos, pois com os conceitos espontâneos que são gerados a partir das experiências pessoais deles com os signos, mais a mediação realizada pela professora, eles conseguem resolver problemas que sozinhos não conseguiriam, ou seja, esses avanços não ocorreriam de forma espontânea, sem essa intervenção.

Ressaltamos que colocar em prática as etapas do ENCl juntamente com os instrumentos culturais, exige da professora um planejamento com objetivos e estratégias claras e detalhadas por conta do processo de conceituação científica, sobre os instrumentos psicológicos a serem desenvolvidos como: a linguagem, os desenhos e os sinais. Além do conhecimento específico das Ciências que a professora precisa ter se apropriado.

Assim, considerando a prática formativa vivenciada, destacamos a importância de existir um espaço formativo sobre 0 Ensino de Ciências para as professoras que atuam nos anos iniciais do Ensino Fundamental, a fim de que elas estudem e melhor compreendam sobre a inserção do Ensino de Ciência desde os primeiros anos e que possam empreender movimentos prospectivos "novas ações, perguntas, planejamentos e melhorias" (GÜLLICH, 2013, p. 289) e retrospectivos "sempre olhando para trás para buscar justificação" (GÜLLICH, 2013, p. 289).

Finalizamos evidenciando que é nesses espaços que a professora encontra a oportunidade de continuar aprendendo, de refletir na e sobre a sua prática, de compreender os problemas enfrentados em sala de aula, de analisar os currículos dos anos iniciais, de socializar com as colegas de profissão sobre as vivências e as experiências, e assim, ter a chance de avançar em direção a novas aprendizagens, mantendo-se em constante exercício de prática colaborativa e reflexiva.

\section{REFERÊNCIAS}

ALARCÃO, Isabel. Professores reflexivos em uma escola reflexiva. 8. ed. São Paulo: Cortez, 2011.

ANDRADE, Guilherme Trópia Barreto de. Percursos históricos de ensinar Ciências através de atividades investigativas. Revista Ensaio, Belo Horizonte, v. 13, n. 1, p. 121-138, 2011.

BERVIAN, Paula Vanessa. Processo de Investigação-Formação-Ação docente: uma perspectiva de constituição do conhecimento tecnológico pedagógico do conteúdo. Orientadora: Maria Cristina Pansera de Araújo. 2019. 223 f. Tese (Doutorado em Educação nas Ciências) - Universidade Regional do Noroeste do Estado do Rio Grande do Sul - UNIJUÍ, ljuí, 2019.

BOZZA, Morgana; SAUER, Laurete Zanol. Contribuições da resolução de problemas no âmbito de uma formação continuada com professores dos anos iniciais. Vidya, Santa Maria, v. 40, n. 2, p. 223-243, 2020. Disponível em: https://bit.ly/ 3n762iW. Acesso em: 6 maio 2021. 
CARR, Wilfred; KEMMIS, Stephen. Teoria Crítica de la enseñanza: investigación-acción en la formación del professorado. Barcelona: Martinez Roca, 1988.

CAPECCHI, Maria Candida Varone de Morais. Problematização no ensino de Ciências. In: CARVALHO, Anna Maria Pessoa de (org.). Ensino de Ciências por Investigação: Condições para implementação em sala de aula. São Paulo: Cengage Learning, 2019. cap. 2, p. 21-39.

CARVALHO, Anna Maria Pessoa de. 0 ensino de Ciências e a proposição de sequências de ensino investigativas. In: CARVALHO, Anna Maria Pessoa de (org.). Ensino de Ciências por Investigação: Condições para implementação em sala de aula. 5 ed. reimpressão da primeira edição de 2013. São Paulo: Cengage Learning, 2019. cap. 1, p. 1-20.

EIDT, Nadia Mara; DUARTE, Newton. Contribuições da teoria da atividade para o debate sobre a natureza da atividade de ensino escolar. Psicologia da Educação, São Paulo, v. 24, p. 51-72, 2007. Disponível em: https://bit.ly/3vvbeAR. Acesso em: 27 maio 2021.

FACCI, Marilda Gonçalves Dias. Valorização ou esvaziamento do trabalho do professor? Um estudo crítico-comparativo da Teoria do Professor Reflexivo, do Construtivismo e da Psicologia Vigotskiana. Campinas: Autores Associados, 2004.

FONTANA, Roseli A. Cação. Como nos tornamos professoras?. 3. ed. Belo Horizonte: Autêntica, 2005.

GIL, Antônio Carlos. Métodos e Técnicas de Pesquisa Social. São Paulo: Atlas, 1987.

GÜLLICH, Roque Ismael da Costa. Investigação-formação-ação em ciências: um caminho para reconstruir a relação entre livro didático. Editora Appris. Curitiba: Brasil, 2013.

LÜDKE, Menga; ANDRÉ, Marli Eliza Dalmazo Afonso de. Pesquisa em Educação: Abordagens qualitativas. São Paulo: E.P. U., 1986.

MALDANER, Otavio Aloisio. Formação de Professores para um Contexto de Referência Conhecido. In: MALDANER, Otavio Aloisio; NERY, Belmayr Knopki (org.). Formação de Professores: Compreensões em Novos Programas e Ações. ljuí: Unijuí, 2014. cap. 1, p. 15-41.

MARTINS, Isabel Cristina dos Santos; LIMA, Valderez MArina do Rosário. Análise Textual Discursiva em movimento. In: LIMA, Valderez Marina do Rosário; RAMOS, Maurivan Güntzel; PAULA, Marlúbia Corrêa de (org.). Métodos de Análise em Pesquisa Qualitativa: Releituras Atuais. Porto Alegre: EDIPUCRS, 2019. cap. 3, p. 77-100.

MORAES, Roque; GALIAZZI, Maria do Carmo. Análise textual discursiva. 3. ed. Editora Unijuí. ljuí: Brasil, 2016.

OLIVEIRA, Zilma de Moraes Ramos de. Educação Infantil: fundamentos e métodos. 7. ed. São Paulo: Cortez, 2011.

PESSANO, Carolina Schaan. Contribuições da área de recursos humano para a seleção de professores - estudo de caso em uma instituição de Ensino Superior de Porto Alegre. Orientador: Claus Dieter Stobäus. 2016. Dissertação (Mestrado em Educação) - Mestranda, Porto Alegre, 2016. Disponível em: https://bit.ly/3C4Qen5. Acesso em: 23 maio 2021.

PIEPER, Quédina; SANGIOGO, Fábio André. Linguagem na formação de professores de Química. Repositório Institucional da UFPel - Guaiaca, Pelotas, 2020. Disponível em: https://bit.ly/3C2MxhB. Acesso em: 18 maio 2021. 
PORLÁN, Rafael; MARTÍN, José. El diario del profesor. Sevilla: Díada Editora, 1997.

REGO, Teresa Cristina. Vygotsky: Uma perspectiva histórico-cultural da educação. Petrópolis: Vozes, 1995.

SASSERON, Lúcia Helena; DUSCHL, Richard Allan. Ensino de Ciências e as Práticas Epistêmicas: 0 papel do professor e 0 engajamento dos estudantes. Investigações em Ensino de Ciências, [s. I.], v. 21, n. 2, p. 52-67, 2016.

SCARPA, Daniela Lopes; SILVA, Maíra Batistoni e. A Biologia e o ensino de Ciências por investigação: dificuldades e possibilidades. In: CARVALHO, Anna Maria Pessoa de (org.). Ensino de Ciências por Investigação: Condições para implementação em sala de aula. São Paulo: Cengage Learning, 2019. cap. 8, p. 129-152.

SILVA, Fábio Augusto Rodrigues e. 0 Ensino de Ciências por Investigação na Educação Superior: um ambiente para 0 estudo da aprendizagem científica. Orientador: Eduardo Fleury Mortimer. 2011. 328 f. Tese (Doutorado em Educação) - Faculdade de Educação, Universidade Federal de Minas Gerais, Belo Horizonte, 2011.

SOLINO, Ana Paula; SASSERON, Lúcia Helena. Investigando a significação de problemas em sequências de ensino investigativa. Revista Investigações em Ensino de Ciências - IENCI, Porto Alegre, v. 23, n. 2, p. 104-129, 2018. Disponível em: https://bit.ly/2Zalx12. Acesso em: 6 maio 2021.

VIGOTSKI, Lev Semyonovich. A construção do pensamento e da linguagem. Tradução Paulo Bezerra. 2. ed. São Paulo: WMF Martins Fontes, 2009. p. 496.

VIGOTSKI, Lev Semenovich; LURIA, Alexander Romanovich; LEONTIEV, Alex Nikolaevich. Linguagem, Desenvolvimento e Aprendizagem. 11. ed. São Paulo: Ícone, 2010.

VYGOTSKY, Lev Semyonovich. A formação social da mente. 4. ed. São Paulo: Livraria Martins Fontes Editora Ltda, 1991. Disponível em: https://bit.ly/2ZhJpjM. Acesso em: 5 abr. 2021.

WENZEL, Judite Scherer; ZANON, Lenir Basso; MALDANER, Otavio Aloisio. A constituição do professor pesquisador pela apropriação dos instrumentos culturais do fazer pesquisa. In: ECHEVERRÍA, A. R.; ZANON, L. B. (Org.). Formação superior em Química no Brasil: práticas e fundamentos curriculares. Injuí: Ed. Unijuí, 2010. p. 67-91

RECEBIDO EM: 31 maio 2021

CONCLUÍDO EM: 01 out. 2021 